\title{
Instituições de Ensino Superior no Brasil: pressupostos constitutivos da realidade contemporânea
}

\section{Daniela Andreza Rodrigues Bartholo ${ }^{1}$}

\section{Resumo}

Este artigo faz parte do projeto de pesquisa denominado: A construção do objetivo institucional da Faculdade do Educador: da idealização à materialização - do Doutorado em andamento em Linguística Aplicada e Estudos da Linguagem - Linguagem e Educação pela Pontifícia Universidade Católica de São Paulo, São Paulo, Brasil/CAPES e intenciona apresentar marcos importantes no processo histórico que originaram as Instituições de Ensino Superior (IES), contextualizando o papel do Ministério da Educação na atual configuração do ensino superior no Brasil. Para compreender os reflexos da historicidade constitutiva das IES, fez-se necessária a explicitação de vertentes político, social, econômico e cultural que influenciaram, dentro de um cenário globalizado, a conjectura atual superdiversa das IES. Outros aspectos também são trazidos para esse campo de discussões e referem-se ao contexto das políticas públicas para o Ensino Superior, o papel de influência exercido pelo Ministério da Educação e às questões mercadológicas que permeiam atividades institucionais.

Palavras-chave: Cenário globalizado. Instituições de Ensino Superior. Ministério da Educação.

\begin{abstract}
This article is part of the research project called: The construction of the institutional objective of the Faculty of Educator: from idealization to materialization - the PhD in progress in Applied Linguistics and Language Studies - Language and Education by the Pontifical Catholic University of São Paulo Paulo, São Paulo, Brazil / CAPES and intends to present important milestones in the historical process that originated the Institutions of Higher Education (HEI), contextualizing the role of the Ministry of Education in the current configuration of higher education in Brazil. In order to understand the reflexes of the constitutive historicity of HEIs, it became necessary to make explicit the political, social, economic and cultural aspects that influenced, within a globalized scenario, a current super-diverse conjecture of HEIs. Other issues are also brought to the field of discussion and refer to the context of public higher education tasks, the role played by the Ministry of Education, and marketing issues affecting institutional activities.
\end{abstract}

Keywords: Globalized scenario. Higher education institutions. Ministry of Education.

\footnotetext{
Doutora pela Pontifícia Universidade Católica de São Paulo - PUC/SP, no Programa de Linguística Aplicada e Estudos da Linguagem (LAEL). E-mail: dani.bartholo@gmail.com
} 
Ensino Superior no Brasil: contornos político, econômico, histórico, social e cultural

Acontecimentos histórico-sociais culminaram para a evolução do cenário educacional, sobretudo às passagens e transições vivenciadas no âmbito do nível de ensino superior.

Nesse sentido, em sua trajetória histórica, a expansão da instituição universitária recebeu influências dos contextos político, econômico, social e cultural ao longo de diversos períodos, caminhando expansivamente na dinâmica dos séculos.

A esse respeito, Trindade (2000, p. 122) aborda quatro períodos relevantes à constituição de faculdades no Brasil: $1^{\circ}$ Do século XII até o Renascimento, caracterizado como "período da invenção da universidade em plena Idade Média em que se constituiu o modelo da universidade tradicional e da sua implantação em todo território europeu sob a proteção da Igreja"; $2^{\circ}$ No século XV, época em que a universidade renascentista recebe o impacto das transformações comerciais do capitalismo e do humanismo literário e artístico; $3^{\circ}$ Já no século XVII tem-se um período marcado por descobertas científicas em vários campos do saber, e a partir do Iluminismo do século XVIII, a universidade começou a institucionalizar a ciência, tornando os saberes de cunho científico; $4^{\circ}$ No século XIX, implantou-se a universidade estatal moderna e é essa etapa que se desdobra até os dias atuais, pois a partir do referido momento, tem-se o estabelecer de uma relação entre Estado e universidade. O Brasil foi afetado por esses acontecimentos.

Nesse sentido, por quase trezentos anos, no cenário educacional brasileiro somente existiam atividades escolares de catequese que eram conduzidas por jesuítas. Nesse período, foram criados vários colégios e seminários, mas a população brasileira era totalmente desprovida de ensino superior local, pois somente os estrangeiros e membros oriundos das famílias abastadas possuíam educação superior, contudo, eram formados em outros países, Portugal, por exemplo.

A transferência da família real e de toda corte portuguesa em 1808 para a colônia (Brasil) colaborou com a instauração das primeiras iniciativas culturais no país. Assim, ainda que tardiamente, algumas faculdades foram criadas mesmo sob a ausência de professores com formação adequada. Os professores que aqui lecionavam eram oriundos de outros países para atender as dez faculdades implantadas no século XIX (DURHAM, 2005).

Contudo, Silva (1969) lembra que após quatorze anos da Proclamação da Independência que o governo iniciou um movimento de criação de instituições de ensino secundário privado e público, tendo como referência a Reforma de Coutto Ferraz de 1854. A Reforma trouxe a regulamentação do ensino primário e secundário seguindo o modelo francês que destinava à burguesia o eleger dos conteúdos que seriam ensinados a partir dos moldes de valores e ideais próprios. Silva (1969) também afirma que o ensino secundário exigia que o candidato possuísse condições mínimas de inteligência geral e de aptidões para estudos acadêmicos, visto que o objetivo era o de formar alunos para ocuparem profissões consideradas intelectuais. Nesse processo, o ensino secundário deixou de se dedicar exclusivamente à formação eclesiástica, abrindo espaço para a formação civil e militar.

A industrialização do país trouxe, além das transformações econômicas, culturais e urbanas, a disseminação de ideias para reformar todo o ensino brasileiro, abarcando também o nível superior a partir da substituição de algumas escolas autônomas por universidades. 
Já no século XX, a integração de algumas faculdades isoladas viabilizou a criação das primeiras universidades brasileiras. Em 1909 foi fundada a Universidade da Amazônia-Manaus; em 1912, a Universidade Federal do Paraná-Curitiba e em 1920, a Universidade Federal do Rio de Janeiro. Assim, nas primeiras três décadas do século XX o número de estabelecimentos de ensino superior passou de 24 para 133. Só na década de 1920 foram criadas 86 desse total. Da década de 1930 ao ano de 1968, o número de estabelecimentos de ensino superior subiu para 693 (TEIXEIRA, 1989).

A criação das universidades, atrelada a uma nova conjuntura social, culminaram com um novo conjunto de exigências e, em lugares de maior aglomeração populacional, São Paulo e Rio de Janeiro, por exemplo, houve maior demanda para o ensino e, as exigências reguladoras, foram requeridas em maior proporção.

Cabe lembrar que, o surgimento do ensino superior no país se deu sob a forma de cátedra. A cátedra era composta por faculdades de medicina, direito e engenharia, modelo esse repensado na época do governo de Getúlio Vargas e da criação do Ministério da Educação e Saúde.

Assim, por meio de uma série de decretos advindos do órgão federal, as mudanças ocorreram. Os Estatutos das Universidades Brasileiras também tiveram um papel importante ao desenhar a organização do ensino superior a partir da instituição do regime universitário. A criação de uma Faculdade de Educação, Ciências e Letras ratificou esse cenário sob o pressuposto de que professores deveriam ser formados (FÁVERO, 2000).

Nesse período, todo o setor privado já estava mais consolidado e as primeiras estatísticas educacionais já demostravam que esse perfil institucional respondiam por cerca de 44\% das matrículas e por $60 \%$ dos estabelecimentos de ensino superior.

É notório que a reforma ocorrida no governo Vargas instituiu as universidades e definiu um padrão de viés legal que seria idealizado à concepção de novas instituições de ensino, porém essa reforma não propôs a eliminação das escolas autônomas e não negou a liberdade para a iniciativa privada. A esse respeito, Durham (2005) comenta que a universidade já nasceu conservadora, pois seu modelo consistia, em grande parte, numa confederação de escolas que preservariam a autonomia anteriormente obtida.

Nesse cenário, tem-se em 1934 a fundação da Universidade de São Paulo (USP) sob o cunho de primeira universidade moderna por trazer o tripé: Ensino-Pesquisa-Extensão em seu projeto político-ideológico. Boa parte do corpo docente era importada de outros países. Em seu processo conceptivo, a USP tem sua origem em meio a confrontos, negociações e compromissos que envolviam intelectuais e setores integrantes da própria burocracia estatal que intencionavam preservar a autonomia institucional. Paralelamente é pertinente lembrar que o Brasil foi o último país americano a criar uma universidade, pois em síntese a criação das universidades antes da USP foi um processo de sobreposição de modelos e não de substituição do que existia até então (DURHAM, 2005).

Contudo, o contexto da Segunda Guerra Mundial trouxe mudanças significativas em diversas partes do mundo, inclusive no Brasil. A necessidade de conhecimentos científicos para o desenvolvimento do país ficou evidente em várias áreas, principalmente na segurança. Nessa mesma época, foi criada a Sociedade Brasileira para o Progresso da Ciência (SBPC) que favoreceria, também, o crescimento do país.

No ano de 1951, década seguinte ao contexto anteriormente apresentado, foram instituídos o Conselho Nacional de Pesquisas (CNPq) com o papel de coordenar o desenvolvimento científico e tecnológico do país e, a Coordenação de Aperfeiçoamento de Pessoal de Nível Superior (CAPES), incumbida da formação de docentes e pesquisadores. 
No ano de 1965, a CAPES inicia a regulamentação da Pós-Graduação aprovando os cursos de mestrado e doutorado no país, processo esse favoreceu a expansão da qualificação acadêmica. Com toda essa evolução, as Instituições de Ensino Superior (IES) brasileiras, dispondo de docentes qualificados, criaram os cursos de graduação em várias áreas de conhecimento e formação.

Desse modo, compreende-se que a expansão do ensino superior brasileiro ocorreu muito mais pela multiplicação de instituições do que pela ampliação de unidades já existentes. Esse fato ocorreu como forma de pressão da sociedade que estava em um processo de mudança, principalmente em relação a crescente aspiração do nível de ensino.

As demandas das camadas sociais em ascensão configuraram uma nova clientela para o ensino superior. O novo mercado de trabalho disputado pelas classes médias impôs a necessidade de se obter uma formação específica e o diploma de ensino superior favoreceria a inserção e acesso ao mercado de trabalho em processo de transformação. É nessa época que se consolida o ensino superior privado no país, com as instituições isoladas privadas mais antigas datadas do período de 1945-1961 (SAMPAIO, 2000).

Por outro lado, o regime militar promoveu uma profunda reforma no ensino superior, culminando à extinção da cátedra, ao fim da autonomia total das faculdades, à criação de institutos, faculdades e/ou escolas, introdução do sistema de créditos, ciclo básico antes da formação profissional, garantia da representação discente e docente (com controle), ingresso contínuo por carreiras e currículos mínimos fixados pelo MEC, tudo isso em prol da maior padronização e controle, portanto menor flexibilidade nos assuntos relacionados à educação, às intenções de formação (SAMPAIO, 2000).

Acordos como MEC-USAID ${ }^{2}$ foram instituídos no país justificando uma mudança ideológica sob o direcionamento dos Estados Unidos. Esse acordo objetivou uma reforma em todos os níveis de ensino brasileiros, adotando-se o modelo americano, principalmente no ensino superior. A intenção era promover uma formação técnica para o plano de desenvolvimento econômico do país orientado a corresponder à política norte-americana que "somente encontrou terreno político propício com o considerado Golpe de 1964. Momento do qual militares, de forma francamente explícita, se alinharam à política econômica capitalista norte-americana" (ARAPIRACA, 1982, p. 178).

O acordo caracterizou-se pela renúncia do governo brasileiro, em favor dos assessores americanos no planejamento e na reforma do ensino com o objetivo oculto de preparar a mão de obra necessária para grandes corporações estrangeiras, carentes dessa qualificação, que se instalaram no território brasileiro.

Já na década de 1970, o resultado de um grande desenvolvimento econômico beneficiou a classe média brasileira e as práticas de consumo levando ao aumento, também, da demanda pelo ensino superior. Durante esse período, tanto o setor público quanto o setor privado, foram beneficiados com os resultados da política econômica do regime militar e do aumento dos recursos federais destinados ao orçamento da educação.

No Brasil, ao contrário de alguns países da América Latina, a repressão política promoveu o ensino superior com um aumento de número de matrículas de 95.961 mil em 1960 para 134.500 mil em 1980. Esse crescimento está relacionado ao crescimento das camadas médias e às novas oportunidades de trabalho em função da favorável economia (SAMPAIO, 2000).

${ }^{2}$ Ministério da Educação (MEC) - United States Agency Development (USAID). 
Soares (1996) diz que na década de 1980, em decorrência de um cenário de crise de endividamento dos países da América Latina, o Banco Mundial (BM) começa a ganhar força estratégica para que os países com dívidas econômicas, inclusive o Brasil, pudessem se reestruturar. Desse modo, o BM deixaria de cumprir o papel exercido nas décadas anteriores, de 1960 e 1970, de um banco de desenvolvimento e indutor de investimentos para assumir uma posição de representante dos interesses de grandes grupos internacionais. Assim, o BM tornou-se o principal responsável para o asseguramento de pagamentos de dívida externa aos credores, concomitantemente, pelo empreendimento da reestruturação e abertura dessas economias a fim de adequá-las à globalização e ao capitalismo-neoliberal.

Por falar em capitalismo-neoliberal e embora esta discussão permeie todo este trabalho e será retomada posteriormente, cabe lembrar que capitalismo tem a lógica inerente de acumulação e funciona sob a base ideológica neoliberalista que, dentre outros aspectos de importância, reconhece que o mercado é quem sinaliza as regras de funcionamento da sociedade (HARVEY, 2013).

Aos países endividados restou a realização de empréstimos junto a bancos como BM e Fundo Monetário Internacional (FMI). A incumbência nuclear desses bancos, além do asseguramento de pagamento da dívida externa aos credores privados, era a estruturação do neoliberalismo, em substituição ao fordismo de base ideológica chamada de Estado do Bem Estar. Contudo, aos países requerentes de empréstimos foram impostas algumas condições para que fosse bem sucedida a implementação do ideário neoliberal. Os ajustes deveriam acontecer em âmbitos distintos abarcando vertentes estruturais, econômicas e sociais (SOARES, 1996).

O fato é que a implementação de uma política educacional requer a utilização de recursos financeiros. Estratégias e ações do âmbito de qualquer governo precisam de subsídios para maior efetividade. Ao pensar na educação, a premissa é a mesma.

A educação pública, por exemplo, pode ser financiada por externos que advêm de bancos como BM e FMI ou obtidos internamente por meio da arrecadação tributária de estados, municípios e União. Os recursos obtidos internamente são de maior volume, mas os provenientes de instâncias internacionais como BM e FMI obtiveram maior poder de influência ideológica às políticas públicas para a educação brasileira desde a década de 1980 (SOARES, 1996).

Paralelo ao contexto elencado anteriormente, iniciou-se a democratização do país na década de 1980 e, consequente publicação da Constituição Federal de 1988 outras normas gerais do ensino foram consolidadas. Assim, em 1996 a Lei de Diretrizes e Bases da Educação Nacional n 9394 (LDBEN) confirmou a mudança do formato da educação brasileira trazendo elementos legisladores e reguladores para toda a educação nacional. A LDBEN foi imprescindível à promoção de rápidas mudanças no ensino superior e para o aumento considerável de instituições privadas no país.

O engendramento político do âmbito federal favoreceu o processo de expansão das IES e, se por um lado os incentivos e flexibilização nos processos de abertura de IES e cursos permitiram que diferentes classes sociais tivessem acesso ao ensino superior, por outro, pode ter negligenciado a obtenção de uma formação que realmente oportunize a transformação individual e social. 
Para tanto,

Marx e Engels, aplicando a lei da contradição existente entre as forças produtivas e as relações de produção, a contradição entre as classes exploradoras e as classes exploradas, a contradição entre base econômica e a superestrutura, a política e a ideologia, e como essas contradições conduzem inevitavelmente às diferentes revoluções sociais em diferentes sociedades de classe (GADOTTI, 2003, p.29).

Assim, a grande expansão do ensino superior em meados dos anos de 1980 não foi planejada pelo setor público, portanto este não se preparou para o crescimento elevado e rápido que ocorreu. Por outro lado, o setor privado foi capaz de absorvê-lo porque concentrou a oferta de cursos com baixo custo e estabeleceu exigências acadêmicas menores, tanto para o ingresso, como para o prosseguimento dos estudos até o nível de ensino superior (graduação).

A educação superior no Brasil abrange cursos e modalidades de ensino diferenciados. Os cursos de graduação representados pelos Bacharelados, Licenciaturas e Tecnólogos nas modalidades, presencial e a distância, confirmam essa diversidade e anunciam os objetivos distintos de formação existentes. Nesse contexto, é sabido que para iniciar a oferta de um curso de graduação, a IES depende de autorização do Ministério da Educação.

O ensino superior brasileiro é, em sua maioria, oriundo da iniciativa privada que representa $88 \%$ das IES existentes. Quanto ao total de cursos no país, 66\% pertencem à iniciativa privada, representado $89 \%$ das vagas disponíveis. Nesse contexto, nos últimos anos a procura por cursos de Licenciatura obteve um decréscimo significativo. Por outro lado, o curso de Licenciatura em Pedagogia durante muitos anos é o que detém o maior número de alunos, segundo o Censo de 2015.

O mesmo Censo divulgou a divisão em percentuais do conjunto existente de cursos de Licenciatura e Bacharelado no Brasil nos âmbitos público e privado. São 4365 cursos de Licenciatura no âmbito público contra 3555 na rede privada e, 5339 cursos de Bacharelado em instituições públicas contra 12566 no âmbito privado.

Essa realidade traz à tona outros elementos de análise, pois no cenário educacional foi integrada a modalidade de educação a distância que, segundo o Censo, tem-se que mais de 15\% das matrículas em ensino superior são em cursos de ensino a distância (EaD). Nesse sentido, são oferecidas atualmente mais de 1,2 mil opções nesta modalidade para os distintos níveis acadêmicos. As IES privadas detém 86,6\% desse portfólio, sendo as Licenciaturas os cursos de maior número de concluintes.

Outro elemento no cenário educacional brasileiro é a educação superior para formação tecnológica. Atualmente esse tipo de curso tem-se 13,6\% no número total de matrículas na educação superior. Em 2003, por exemplo, esse percentual era 2,9\%, portanto em dez anos (entre 2003 e 2013), a matrícula cresceu de 115 mil para quase um milhão, tendo um crescimento médio anual de $24,1 \%$, sendo a grande parte dessas matrículas efetivadas em instituições privadas e, estas têm $85,6 \%$ do total de matriculas efetivadas.

Os dados relativos ao ano de 2015 que foram divulgados pelo Instituto Nacional de Estudos e Pesquisas Educacionais Anísio Teixeira (Inep) revelam que 8.033.574 alunos estão matriculados no ensino superior ofertados em, um pouco mais de 32 mil cursos de graduação em 2.390 IES. Das 6,1 milhões de novas vagas em instituições públicas e privadas, somente $54,1 \%$ estão preenchidas. 
De acordo com os dados do último censo, o país apresenta a maior privatização das IES em relação a outros países do mundo. Esse fato ocorre em decorrência da multiplicação das instituições privadas nos últimos 50 anos, principalmente com os incentivos advindos de programas governamentais que estimulam o ensino superior por meio de financiamentos, tais como, o Fundo de Financiamento Estudantil (FIES), Programa Universidade para Todos (ProUni), dentre outros que visam à ocupação de vagas no ensino privado.

Por outro lado, o Decreto $\mathrm{n}^{\circ} 5.773$ do ano de 2006 dispõe sobre o exercício das funções de regulação, supervisão e avaliação das IES e de cursos superiores de graduação e em seu Artigo $9^{\circ}$ descreve: "A educação superior é livre à iniciativa privada, observadas as normas gerais da educação nacional e mediante autorização e avaliação de qualidade pelo Poder Público". Essa premissa impõe que qualquer instituição de ensino só funcionará se for credenciada junto ao órgão regulador do MEC.

A Secretaria de Regulação e Supervisão da Educação Superior (SERES) do MEC é o órgão que autoriza o funcionamento de novos cursos de graduação nas unidades da federação. Compete a Seres regular e supervisionar as instituições de educação superior, públicas e privadas do país. O MEC estabelece itens específicos para o credenciamento das instituições de educação superior, conforme a seguir:

- Para iniciar suas atividades, as IES devem solicitar o credenciamento junto ao MEC. De acordo com sua organização acadêmica, as IES são credenciadas como faculdades, centros universitários e universidades.

- Inicialmente a IES é credenciada como faculdade. O credenciamento como universidade ou centro universitário, com as respectivas prerrogativas de autonomia, depende do credenciamento específico de instituição já credenciada, em funcionamento regular e com padrão satisfatório de qualidade.

- O primeiro credenciamento da instituição tem prazo máximo de três anos, para faculdades e centros universitários, e de cinco anos para as universidades.

- O recredenciamento deve ser solicitado pela IES ao final de cada ciclo avaliativo do Sistema Nacional de Avaliação da Educação Superior (SINAES), junto à secretaria competente.

O processo de reconhecimento de cada curso deve ser solicitado quando parte do mesmo já transcorreu, desde que observada a legislação pertinente ao tipo de curso. A renovação de reconhecimento dos cursos é obrigatória e ocorrerá de acordo com os conceitos obtidos na avaliação. Esses processos também podem ser vistos como uma oportunidade de revisão e ajustes, viabilizando à IES um repensar de sua condição como fornecedora de serviços educacionais de modo a reavaliar os diversos aspectos relativos a qualidade do curso que foi reconhecido.

Dentro do processo de avaliação dos cursos, o MEC/INEP instituiu um novo indicador a fim de estabelecer critérios e objetivos de "qualidade e excelência" dos cursos. De acordo com o mesmo órgão, existe o que se chama de "Conceito Preliminar de Curso (CPC) que se refere às notas de 1 a 5, sendo este um indicador prévio da situação dos cursos de graduação no país" (MEC/INEP, s/d).

"Para que os valores se consolidem, e representem efetivamente o que se espera de um curso em termos de qualidade e excelência, comissões de avaliadores farão visitas in loco para corroborar ou alterar o conceito obtido preliminarmente" (MEC/INEP, s/d).

O CPC é anualmente divulgado juntamente com os resultados do ENADE e trazem implicações às IES. Os cursos que obtiverem CPC 1 e 2 serão automaticamente incluídos no cronograma de visitas dos avaliadores 
do INEP. Já os cursos que obtenham conceito igual ou maior que 3, terão a opção de não receber a visita dos avaliadores e, assim, transformar o CPC em conceito permanente. Esses cursos de conceito 3 são cursos que estão em consonância plena com os critérios de qualidade estabelecidos para continuarem a funcionar. Os cursos com conceito 5 são chamados de cursos de excelência e servirão de modelo de referência para subsidiar o processo de regulação dos cursos de graduação no Brasil.

Contudo, desde o ano de 2007, o MEC atua com o sistema eletrônico e-mec que aperfeiçoou o processo de regulação dos cursos e instituições de ensino existentes. A ferramenta possibilita a tramitação eletrônica dos processos de regulamentação da oferta de ensino superior no país. Portanto, sob o uso da internet, as IES fazem o credenciamento e o recredenciamento, buscam autorização, reconhecimento e renovação de reconhecimento de seus cursos. Conforme informações do MEC, o sistema permite que as IES realizem a abertura e, consequente acompanhamento de processos com maior lisura.

Para iniciar a oferta de um curso de graduação, a IES depende de autorização do MEC. A exceção são as universidades e centros universitários que, por terem maior autonomia, independem de autorização para o funcionamento de curso superior. No entanto, essas instituições devem informar à secretaria competente os cursos abertos para que sejam supervisionados, avaliados e, assim, obtenham o reconhecimento. O reconhecimento deve ser solicitado pela IES quando o curso de graduação tiver completado 50\% de sua carga horária, sendo condição necessária para a validade nacional dos respectivos diplomas.

\section{Global-mundo e a realidade dos contextos institucionais superdiversos no Brasil}

A sociedade contemporânea é reconhecida como um contexto de época marcado pelos efeitos da globalização que traz, dentre outros a peculiaridade da dinâmica mutável de espaços, pessoas, informações etc.

Nesse sentido, a globalização integra "conjuntos de relações sociais que se traduzem na intensificação das interações transnacionais, sejam elas práticas interestatais, práticas capitalistas globais ou práticas sociais e culturais transnacionais", sendo a globalização algo decorrente das escolhas e ações advindas de chefes de Estado, economistas, empresários etc. (BOAVENTURA SANTOS, 2002, p.85).

Sob a lógica global, o mundo se movimenta rapidamente em suas mais diversas dimensões e as instâncias são marcadas por recomeços que legitimam o fluxo da mutabilidade, do dinamismo. A constância desse movimento na sociedade atual concebe a inércia como algo inexequível, pois, segundo Bauman (1999), as forças globais atuam contrariamente à lógica da fixação, da imutabilidade, da estabilização etc.

A característica mutável do mundo atual afeta espaços físicos (locais, regionais e/ou mundiais), fragiliza as crenças, valores e conceitos arraigados historicamente, interfere no modo conceptivo das relações sociais, influencia à dinâmica e tendências do mercado, impinge às práticas sociais outras incumbências etc., por fim, prescreve globalmente as diretrizes para as vertentes social, política, econômica e cultural (BAUMAN, 1999; MOITA LOPES, 2010; SILVERSTEIN, 1996).

Bauman (1999) esclarece que há uma concordância acerca da existência de uma democracia liberal, entendida como base consonante ao tempo atual no que se refere à gestão pública, que minimiza as barreiras que poderiam impedir e/ou dificultar a fluidez financeira das organizações internacionais e/ou também chamadas de multinacionais. 
Desse modo, a globalização adentra a um cenário de tradicionalismos para favorecer a emergência de contexto transformador repleto de inovações que corroboram, inclusive para o questionamento de axiomas, até então concebidos como universais. Assim, a sociedade global caracteriza-se por ser um contexto múltiplo de países, estados, cidades e espaços sociais, antes percebidos como lugares uníssonos e/ou partes isoladas da totalidade, portanto, afetados somente por suas respectivas especificidades sociais, políticas, econômicas e culturais se reconfigura (BAUMAN, 1999; BOAVENTURA SANTOS, 2002; MOITA LOPES, 2010; SILVERSTEIN, 1996).

Os autores convergem à identificação de contextos locais globalizados e uma realidade global que se faz de maneira localizada. Para tanto, como há a relação de reciprocidade, são mutuamente afetadas. É o caso da globalização econômica, por exemplo.

A globalização econômica é caracterizada pela organização da economia mundial dominada pelo sistema financeiro e pelo investimento à escala global; processos de produção flexíveis e multilocais; baixos custos de transporte; revolução nas tecnologias de informação e de comunicação; desregulação das economias nacionais; preeminência das agências financeiras multilaterais; emergência de três grandes capitalismos transnacionais identificados: americano; japonês e europeu (BOAVENTURA SANTOS, 2002, p. 29).

Portanto, na globalização, a vertente econômica interfere no âmbito da política e esta altera os rumos sociais e os sociais as questões culturais. São inúmeros os exemplos do efeito dominó gerado pelos processos globalizantes, dentre estes: crise econômica de um país afetando outros países e instaurando crises econômicas de amplitude internacional em função da interdependência econômica existente; tendências capitalistas de países de economia hegemônica e, portanto de maior representatividade no mundo, direcionando as vertentes políticas quanto, por exemplo, à abertura de "portas” para importações, exportações que, também impõem necessidades de produção e, a produção ditando novos padrões de moda, comportamento, valores etc.

Características como essas permitem, por exemplo, que produtos de uma dada cultura sejam deslocados para outras culturas em distintas sociedades, culminando com um processo de hibridização no qual produtos culturais não seriam meramente assimilados e/ou multiplicados em outros contextos de realidade segundo Boaventura Santos (2002), mas sim hibridizados e/ou miscigenados.

Cabe ressaltar que a transnacionalização também acontece em fluxos migratórios e em movimentos sociais, portanto não se restringe às questões de âmbito econômico, simultaneamente a globalização transcende a vertente político-econômica e adentra no âmbito das questões culturais e sociais que, sob o avanço tecnológico e surgimento da internet produtos culturais podem estar em diversos lugares do planeta. Contudo, é possível afirmar que os efeitos da globalização ficaram mais perceptivos a partir dos avanços tecnológicos e, consequentemente, a partir da emergência das novas ferramentas de informação advindas das Tecnologias de Informação e Comunicação (TIC).

A concomitância entre processo globalizante e avanço tecnológico configurou uma sociedade denominada de informacional. A sociedade informacional é constituída por redes nas quais a internet é uma espécie de vértebra que, sob o uso de computadores, interliga todas as redes. Contudo, toda rede terá um campo de particularidades culturais e estilos comunicativos decorrentes dos valores expressos e/ou subtendidos em sua organização. A sociedade organizada em redes elucida os mais diversos espaços virtuais, identificando a existência de grupos e comunidades interligadas com seu conjunto específico de particularidades (CASTELLS, 2011). A internet favoreceu significativamente a consolidação do movimento de globalização, primordialmente por tornar quase instantâneo os processos comunicativos entre as redes locais e globais. 
Para tanto, os meios de comunicação criados por ferramentas tecnológicas favoreceram a ruptura de algumas fronteiras que apartavam diferentes sociedades e em escala global tornou-se possível conhecer as mais diversas realidades por intermédio da internet. Desse modo, semelhanças e disparidades entre todos do planeta vieram à tona: a riqueza de alguns países, a pobreza em outros, a diversidade cultural nos distintos níveis - mundial, regional, local pode ser acessada pelos meios de informação e comunicação, entretanto tornaram-se mais latentes a resistência à aceitação das diferenças e ficaram mais evidentes as barreiras que impedem a mobilidade física, social, cultural etc., de muitos seres humanos.

Ao pensar em comunicação em escala global, ressalta-se a necessidade de ser, além de alfabetizado na língua materna ter-se o domínio da língua inglesa, idioma hegemônico, reconhecido em qualquer parte do mundo. Moita Lopes (2008) complementa que a língua inglesa se constitui como ferramenta imprescindível às interações no nível local, especialmente se os participantes locais intencionam as interações com outras realidades de nível global.

Nesse sentido, configura-se a primeira barreira para conceber mobilidade entre todos os seres humanos do planeta, pois adentrar em uma dada sociedade fisicamente ou virtualmente requer domínio da língua que, com o advento da globalização, tornou-se reconhecida e, também requerida universalmente.

Sob outro olhar, a mobilidade física e/ou espacial de fluxos migratórios foi analisada por Vertovec (2007) ao esclarecer que a globalização trouxe à tona a fragilidade das fronteiras de modo a instaurar movimentos de mobilidade social nas extremas vertentes global e local.

As mudanças foram tão significativas com o advento da globalização e com seu processo instaurador que, a diversidade não pôde mais ser compreendida exclusivamente pelo viés cultural. Daí o autor criar o termo superdiversidade compreendendo-o como algo originário e de identificação de uma diversificação da diversidade em contextos de várias línguas e diferentes culturas.

Em tempos de globalização o mundo deixou de ser uma vila e passou a ser uma rede complexa de vilas, aldeias, cidades, bairros, dentre outros, que estão ligados por vínculos tangíveis (materiais) e simbólicos que, quase sempre, são imprevisíveis em função do constante processo de transformação (BLOMMAERT, 2010).

Segundo Blommaert, (2011) e Vertovec (2007) a superdiversidade emerge em meio ao contexto de globalização que, trouxe os avanços das tecnologias que favoreceram a criação de novas mídias e ferramentas, alterando significativamente as mais diferentes sociedades nas dimensões sociais, culturais e linguísticas. A emergência de novos parâmetros culminou com o reconhecimento de importância dos discursos sobre a superdiversidade.

Moita Lopes (2006) complementa os autores ao propor que sejam direcionados olhares sobre os sujeitos colocados à margem e que, portanto, possam ser escutados ao invés de serem apagadas e/ou silenciadas suas vozes.

Blommaert (2011) e Vertovec (2007) esclarecem que, se há uma prevalência de uma vertente, em detrimento de outras, tem-se a manifestação de um posicionamento único que está representado por uma única cultura e assim, pode-se chegar à conclusão de que o silenciar de outras vozes apaga a luz da superdiversidade em contextos heterogêneos como os institucionais, por exemplo.

Assim, embora o conceito de superdiversidade, criado por Vertovec (2007, p.1026 a 1027), tenha sido criado para discorrer acerca de migrantes na Inglaterra, o bojo conceitual de superdiversidade não se restringe à explicitação de questões locais do referido país e, também não se limita às análises de diferentes contextos de imigração, pois suas "variáveis [...] não são novas em si [...], tampouco o são muitas de suas correlações, são a emergência de sua escala, configuração múltipla histórica e produzida por políticas públicas, e condicionamento 
mútuo que agora requerem distinção conceitual”. Nesse sentido, a superdiversidade, sinteticamente, compreende sob o olhar crítico-reflexivo, a manifestação de vozes que estão sobrepostas a todas as outras. Para o autor, a sociedade contemporânea é marcada pela superdiversidade.

Um cenário superdiverso traz à tona diversidades social, cultural e econômica tendo, como consequências de efeito, a maneira como cada pessoa e sociedade organizam suas vidas [...] a superdiversidade aumentou a imprevisibilidade [...] o outro é suposição [...] o outro está sempre em processo de mudança [...] a superdiversidade é norteada por três respectivos conceitos: mobilidade, complexidade e imprevisibilidade (BLOMMAERT, 2010/2011/2012/2013).

Moita Lopes (2006) reforça que a problemática em torno da identidade social contemporânea é compreendida sob a aceitação e reconhecimento de serem todos os sujeitos do planeta heterogêneos, fragmentados e construídos em práticas discursivas situadas historicamente, culturalmente e institucionalmente.

No Brasil as implicações da globalização começaram a ser mais claramente difundidas a partir da década de 1990, período marcado por acontecimentos em todas as instâncias da sociedade como a criação de ordenamentos legais pautados na Declaração Universal dos Direitos Humanos de 1948 e nas tendências político-econômicas de países capitalistas desenvolvidos; maior flexibilização nos processos de importação e exportação; incentivo à entrada de capital estrangeiro no país (indústrias e organizações em geral); maior responsabilidade da sociedade civil; atribuição de competências para as esferas de poder nos níveis federal, estadual e municipal; incentivo financeiro do FMI vinculado à contemplação de certas determinações, como por exemplo, o aumento do nível de escolaridade no país; informatização dos processos de produção; aparecimento e expansão de Organizações NãoGovernamentais e Associações Civis; ampliação do sistema de ensino público (construção de escolas para atender determinações da Constituição Federal de 1988 quanto à universalização do ensino e viabilização do acesso a todos os alunos em idade escolar); maior incentivo fiscal para fomentar a criação de novos empregos; surgimento de novas profissões, inclusive atreladas às TICs; disseminação do discurso de igualdade de direitos e deveres respaldado nos ideários de uma democracia liberal inspirada nos moldes norte-americanos etc.

Assim, a partir da publicação da Constituição Federal em 1988, a sociedade brasileira iniciou um processo de retomada de princípios liberais e de democracia disseminados na década de 1960. Nesse contexto, a retomada do discurso e das práticas de abertura de capital, de liberdade de expressão e maior participação da sociedade civil nas decisões do âmbito das políticas públicas, inclusive para a educação, foram reavivados após a publicação da Carta Magna.

No ano de 1990, os princípios de direitos e deveres inerentes em sociedades que se auto intitulam democráticas foram instaurados em documentos de âmbito federal voltados à educação em amplo sentido. Portanto, em 1990, foi publicado o Estatuto da Criança e do Adolescente (ECA) por meio da Lei nº 8.069 e, em 1996, a nova Lei de Diretrizes e Bases da Educação Nacional (LDBEN), Lei nº 9.394 também é publicada. Os referidos ordenamentos trouxeram textos respaldados em diretrizes internacionais que resguardam os direitos e deveres comuns em sociedades liberais-democráticas.

A ideia, nesse momento, não é prover uma análise crítico-reflexiva das bases de uma democracia e das expectativas que se tem acerca de realidades assim denominadas, mas somente associar os princípios legais que regem a organização da educação no Brasil dentro do contexto de implicações da globalização. Até porque uma discussão dentro do campo de características de uma sociedade realmente democrática requereria um profundo 
diálogo sobre as contradições e disparidades sociais, econômicas, globais, regionais e locais etc., e potencialmente a democracia que dissemina ter na sociedade brasileira seria encontrada num limbo de paradoxos que, muito provavelmente não a confirmariam. A esse respeito, Bauman (1999) chama atenção para o fato de que essa dinâmica fluída globalização e a consequente hibridização destacam uma realidade tipicamente de elites globais e, portanto, deixam de discorrer acerca das consequências negativas advindas da globalização.

Milton Santos (2001) analisa criticamente o movimento imposto pela globalização que obriga a todos assumir ritmos frenéticos que não deixam brecha para a fixação, pois forças globais excluem e/ou retiram do lugar sujeitos e objetos; deixa à deriva um número cada vez maior de pessoas; intencionam eliminar as diferenças entre as pessoas subjugando outras pessoas em prol de um pensamento uníssono, globalizante. Para este autor:

\footnotetext{
Vivemos num mundo confuso e confusamente percebido. Haveria nisto um paradoxo pedindo uma explicação? De um lado, é abusivamente mencionado o extraordinário progresso das ciências e das técnicas, das quais um dos frutos são os novos materiais artificiais que autorizam a precisão e a intencionalidade. De outro lado, há, também, referência obrigatória à aceleração contemporânea e todas as vertigens que cria, a começar pela própria velocidade. Todos esses, porém, são dados de um mundo físico fabricado pelo homem, cuja utilização, aliás, permite que o mundo se torne esse mundo confuso e confusamente percebido (SANTOS, 2001, p.2).
}

Em uma sociedade capitalista e globalizada, as contradições são percebidas na produção e reprodução do capital e seu desenvolvimento se faz de modo dicotômico em meio ao acúmulo e a exclusão, tal como enxergado por Marx (1978). Na visão marxista, o sistema capitalista se desenvolve por meio da acumulação de capital e a reprodução do sistema objetiva a busca permanente de mais-valia e lucro tendo nas relações de exploração o principal elemento que explica a origem do valor e, também, o impulsionador das desigualdades e exclusão dentro de uma sociedade.

Para Teresa Santos (2001, p.1-3) "através da conquista do mercado mundial e da exploração da força de trabalho, os grupos hegemônicos vão impondo seu domínio". Para a autora, a essência do sistema capitalista é o processo de "acumulação, concentração, centralização e internacionalização do capital e tal essência, conduz a uma crescente polarização".

Portanto, segundo esta autora, o capitalismo marginaliza e exclui:
[...] a abrangência da exclusão social, no âmbito internacional, tem tomado enormes proporções, o que a torna algo "disfuncional" ao sistema. No discurso das classes dominantes, os próprios indivíduos são culpabilizados pela sua exclusão do sistema, e as sociedades periféricas são consideradas as principais responsáveis pela sua situação de "atraso" [...] uma consequência transforma-se em causa, encobrindo as reais determinações estruturais da crescente situação de exclusão social: as contradições da acumulação capitalista (SANTOS, 2001, p. 2).

Sob outra perspectiva, Harvey (2013) esclarece que no cenário atual, a globalização em suas distintas perspectivas social, econômica, política e cultural, impulsionam mudanças no contexto mundial ampliando abundantemente conexões e fluxos que estruturam o espaço em ritmos diversos. 
Para o autor, o cenário que se visualiza atualmente é fruto do aprofundamento do neoliberalismo que se institui em um contexto de desregulamentação e flexibilização de regras de mercado e, também, financeiras que têm o apoio de um sistema jurídico de atuação conivente com suas ações de lógica perniciosa. Essas premissas elucidam a desregulamentação gerenciada por regras novas que se constituem no modo de produção capitalista de acumulação flexível.

Nesse sentido, a globalização representa o ápice do processo de internacionalização do mundo capitalista sob três respectivas visões: fábula, perversidade e possibilidade (SANTOS 2001; 2008).

O autor discorre que, "um mundo" que se faz "tal como nos fazem crer", tem-se a explicação da "globalização como fábula". Essa globalização relaciona-se com os mitos que a integram, tais como aldeia global, contração do espaço e tempo, a velocidade do cotidiano e a desterritorialização (2001, p.18).

Ele explica que a interação global acontece por meio da mediação das tecnologias de informação, entretanto, o acesso às ferramentas interacionais não é equitativo e a aldeia global é parcialmente válida.

Por outro lado, tem-se tempo e distância concebidos, também, variavelmente. Já a velocidade do cotidiano será maior ou menor dependendo do uso e vantagens tecnológicas. A desterritorialização não é fidedigna, pois o exercício de cidadania vincula-se diretamente a um Estado Nacional o que desmente a ideia de existir um cidadão global (SANTOS 2001; 2008).

Na segunda vertente de entendimento da globalização tem-se a perversidade. Perversidade é o mundo tal como ele é:

\footnotetext{
De fato, para a grande maior parte da humanidade a globalização está se impondo como uma fábrica de perversidades. O desemprego crescente torna-se crônico. A pobreza aumenta e as classes médias perdem em qualidade de vida. O salário médio tende a baixar. A fome e o desabrigo se generalizam em todos os continentes (SANTOS, 2001, p.19).
}

Para o autor, o caráter perverso da globalização na sociedade contemporânea está baseado em duas violências, sendo estas, a tirania da informação representada pelo modo como ela é distribuída para todas as pessoas e a tirania do dinheiro que é identificada como sendo o motor da vida econômica e social.

Ambas as violências embasam um pensamento único e configuram um novo totalitarismo composto pela competitividade, consumo e confusão dos espíritos culminando com uma nova denominação: globaritarismo (SANTOS, 2008).

A competição distingue-se de concorrência por não envolver regras de convivência. Competição objetiva o alcance de melhores posições estimulando lutas sob o expandir e afrouxar de valores morais, maior individualismo e modos perversos de exercer a sociabilidade. Nesse sentido, tem-se a tirania do consumo que acaba por estreitar a visão de mundo das pessoas (SANTOS, 2008).

Ademais, a competitividade atrelada com consumo tirânico favorece a desordem dos espíritos, contribuindo para o sentimento de insegurança que sustenta e mantém o ciclo vicioso da busca incessante pelo dinheiro. Essa premissa elucida um contexto de perversidade sistêmica peculiarmente percebida pelo crescimento de desigualdades sociais. Contudo, a evolução da perversidade tem seus respectivos limites e estes sinalizam outra vertente de globalização. 
Santos (2008) alerta para o reconhecimento de que os fatos não conseguem dar sustentação ao globaritarismo, uma vez que, existem estratégias paralelas que elucidam a passagem para um novo período histórico. Isso pode ser percebido por meio do surgimento de contraracionalidades.

As contraracionalidades procuram saídas pautadas no homem e confirmam que existem meios objetivos e mentais para se superar a tirania do dinheiro e da informação na sociedade contemporânea. Abre-se, portanto, uma porta de possibilidades ao se pensar em um projeto nacional que seja alternativo e fundamentado nos mesmos artifícios usados pelo capital. Essa abertura viabilizaria o emergir de uma globalização mais humana e civilizatória evidenciando a possibilidade que os seres humanos possuem de ter o controle sobre o mundo, pois para o autor a globalização perversa não é irremediável ou inconversível (SANTOS, 2001, 2008).

No contexto de sociedade globalizada, é possível identificar claramente os contrastes sociais que se intensificam. Fome, violência, pessoas sem moradia e sem condições de sobrevivência são vertentes antagônicas, às mansões luxuosas, ao número elevado de bens, ao supérfluo para se viver. Esse antagonismo traz a tona a riqueza e a demasiada pobreza que se podem ver em sociedades capitalistas.

A realidade educacional brasileira não está imune às influências e consequências do capitalismo. Escolas e Institutos de Ensino Superior, principalmente da rede privada de ensino, também usam de artifícios para se manterem no mercado, obviamente, dentro da lógica capitalista competitiva que ficou ainda mais acirrada após o advento da globalização, especificamente na década de 1990.

A LDBEN organiza a educação escolar básica e superior no Brasil é inspirada nos princípios constitucionais de universalização do ensino público, reforçando a igualdade para o acesso e permanência de alunos de diferentes faixas etárias nas escolas e instituições de ensino superior e, para atender aos princípios elencados, as esferas de poder público federal, estadual e municipal ampliaram sua rede de escolas e sob incumbências distintas, mesmo que corresponsáveis, traçaram reformas à efetivação dos direitos de todos à educação.

Na esfera de poder administrativo federal, dentre outras competências, ficou a responsabilidade de legislar, regulamentar e regular o ensino superior brasileiro nas dimensões públicas e/ou privadas. Sob a intenção de integrar o conjunto de países incentivados pelo FMI, o Brasil precisou "correr atrás" da formação em massa nos mais diferentes níveis de ensino, visto que como parte de exigências do Fundo estava a elevação do nível de escolaridade da população (LACERDA, 1998).

Nesse sentido, iniciou-se na década de 1990 a proliferação de instituições de ensino superior dispostas a formar em grande escala, profissionais para atuar nas diferentes frentes de trabalho. Para tanto, políticas de investimento favoreceram a expansão física das escolas; as parcerias com entidades civis foram firmadas; IES privadas foram beneficiadas com incentivos fiscais etc., a fim de aumentar a demanda de atendimento de alunos no ensino superior. Embora essas questões já tenham sido tratadas na seção 1, a retomada do assunto se faz essencial para o entendimento dos perfis de alunados em grande parte das IES existentes.

No ano de 1997, é publicado o Decreto $n^{\circ} 2.207$ que foi na sequencia alterado pelo Decreto $\mathrm{n}^{\circ} 2.306$ do mesmo ano para regulamentar o Sistema Federal de Educação. Esse documento permitiu ao governo normatizar o conjunto de atribuições das instituições de ensino superior do âmbito privado, reconhecendo instituições com fins lucrativos e ao mesmo tempo, constituindo cinco tipos de instituições de ensino superior, sendo estas as universidades, os centros universitários, as faculdades, faculdades integradas; institutos superiores ou chamadas escolas superiores. 
Desse modo, o Decreto favoreceu a expansão das empresas de ensino superior brasileiro, entretanto, um novo Decreto de $n^{\circ} 3.860$ foi publicado no ano de 2001, alterou a organização desse nível de ensino significativamente, modificando regras inclusive da avaliação de cursos e instituições e, também reconfigurou a tipologia de instituições para: universidades, centros universitários, faculdades e faculdades integradas, institutos superiores, escolas superiores. As IES tiveram sua conjectura mantida, mas foram reagrupadas de outra maneira.

Outras reflexões podem ser extraídas dessa conjuntura, visto que este pode ser o momento de origem do sucateamento da educação; da má formação profissional que veio em detrimento do processo de expansão de escolas e IES; da origem da mercantilização do ensino no Brasil. O crescimento de IES no Brasil, trouxe em concomitância, maior variedade de cursos, maior número de alunos e, também, um contexto superdiverso de IESs.

\section{Referências}

ARAPIRACA, J. de. A USAID e a educação brasileira: um estudo a partir de uma abordagem crítica da teoria do capital humano. São Paulo: Autores Associados: Cortez, 1982

BAUMAN, Z. Globalização: as consequências humanas. Rio de Janeiro: Jorge Zahar, 1999.

BAUMAN, Z. Vida para consumo: a transformação das pessoas em mercadoria. Rio de Janeiro: Zahar, 2008.

BOAVENTURA SANTOS, de S. Os processos da globalização. In: BOAVENTURA SANTOS, de S. (Org.). A globalização e as ciências sociais. São Paulo: Cortez, 2002. p. 25-102.

BOAVENTURA SANTOS, de S. Do pós-moderno ao pós-colonial. E para além de um e de outro. Travessias, Coimbra, n. 6-7, p. 15-36, 2008.

BLOMMAERT, J. Ethnography, Superdiversity and Linguistic Landscapes: Chronicles of Complexity. Bristol, UK: Multilingual Matters, 2013,

BLOMMAERT, J. Chronicles of complexity: Ethnography, superdiversity, and linguistic landscapes. Bristol: Multilingual matters, 2012. $150 \mathrm{p}$.

BLOMMAERT, J.; BACKUS, A. Repertoires revisited: "knowing language" In: superdiversity. Working Papers in Urban Language and Literacies, paper 67. At www.kcl.ac.uk/ldc, 2011.

BLOMMAERT, J. he sociolinguistics of globalization. New York, USA: Cambridge University Press, 2010.

BRASIL. Constituição da República Federativa do Brasil. Brasília. 1988.

BRASIL. Ministério de Educação e Cultura. LDB - Lei no 9394/96, de 20 de dezembro de 1996. Estabelece as diretrizes e bases da Educação Nacional. Brasília: MEC, 1996.

CASTELLS, M. A sociedade em rede. São Paulo: Paz e Terra, 2011. 
DURHAM, E. R. Educação superior pública e privada (1808-2000). In SCHWARTMAN, S.;

BROCK, C. Os desafios da educação no Brasil. Rio de Janeiro: Nova Fronteira, 2005.

FÁVERO, M. de L. de. Universidade e poder: análise crítica/fundamentos históricos: 1930-1945. Brasília: Plano, 2000.

GADOTTI, M. Concepção dialética da educação: um estudo introdutório. 14. ed. São Paulo: Cortez, 2003.

HARVEY, D. Condição pós-moderna. 24. ed. São Paulo, SP: Loyola. 2013.

INEP. Instituto Nacional de Estudos e Pesquisas Educacionais Anísio Teixeira. Disponível em: http:// portal.inep.gov.br/web/guest/sinopses-estatisticas-da-educacao-superior. Acesso em: jan. 2017.

INEP. Censo da Educação Superior 2016. Disponível em: http://download.inep.gov.br/educacao superior/censo_superior/documentos/2016/notas_sobre_o_censo_da_educacao_superior_2016.pdf. Acesso em: 11 maio 2018.

\section{LACERDA, Antônio C. de. O Impacto da globalização na economia brasileira. São}

Paulo: Editora Contexto, 1998.

LACERDA, Antônio C. de. (org.) Desnacionalização: riscos, mitos e desafios.

São Paulo: Editora Contexto, 2000.

MARX, K. El Capital. Crítica de la economía política. México: Siglo Veintiuno Editores, 1978.

MEC. Ministério da Educação e Cultura. Disponível em: http://www4.mec.gov.br/sapiens/portarias/ dec5773.htm. Acesso em: jan. 2017.

MEC. O que é o conceito preliminar de curso? Disponível em: http://portal.mec.gov.br/component/ content/article?id=13074:o-que-e-o-conceito-preliminar-de-curso. Acesso em: 29 maio 2018.

MOITA LOPES, L. P. Identidades fragmentadas: a construção discursiva de raça, gênero e sexualidade em sala de aula. Campinas: Mercado de Letras, 2002.

MOITA LOPES, L. P.; BASTOS, L. C. Para além da identidade: fluxos, movimentos e trânsitos. Belo Horizonte: Editora UFMG, 2010.

SAMPAIO, H. Ensino superior no Brasil: o setor privado. São Paulo: Hucitec: FAPESP, 2000.

SANTOS, M. Por uma outra globalização: do pensamento único à consciência universal. Rio de Janeiro: Record, 2001; 2008.

SANTOS, M. () A natureza do espaço: técnica e tempo, razão e emoção. 4. ed. São Paulo, SP: EdUSP, 2006. 
SANTOS, T. S dos. Globalização e exclusão: a dialética da mundialização do capital. Sociologias, Porto Alegre, ano 3, n. 6, jul/dez, p. 170-198, 2001.

SILVA, G. B. A educação secundária: perspectiva histórica e teoria. São Paulo: Nacional, 1969. 416 p. (Atualidades Pedagógicas, v. 94).

SILVERSTEIN, M; URBAN, G. The natural history of discourse. In: SILVERSTEIN, M; URBAN, G. (Orgs.). Natural histories of discourse. Chicago: University of Chicago Press. 1996

SOARES, M. C. C. () Banco Mundial: políticas e reformas. In: DE TOMMASI, L.; WARDE, M. J; HADDAD, S. O Banco mundial e as políticas educacionais. São Paulo: Cortez, 1996. p. 15-40.

TRINDADE, H. Saber e poder: os dilemas da universidade brasileira. São Paulo: Estudos Avançados, 2000.

VERTOVEC, S. Super-diversity and its implications. Ethnic and Racial Studies, v. 30, p. 6, 2007.

Recebido em 01/10/2018

Aprovado em: 01/04/2019 